\title{
Discriminative stimulus properties of naloxone in Long-Evans rats: assessment with the conditioned taste aversion baseline of drug discrimination learning
}

\author{
Catherine M. Davis • Glenn W. Stevenson • \\ Fernando Cañadas • Thomas Ullrich • Kenner C. Rice • \\ Anthony L. Riley
}

Received: 1 May 2008 / Accepted: 9 June 2008 / Published online: 2 July 2008

(C) Springer-Verlag 2008

\begin{abstract}
Rationale The characterization of the discriminative stimulus properties of naloxone has focused primarily on its actions at the mu opioid receptor, although naloxone also displays an affinity for delta and kappa receptor subtypes. Objectives The present study extends this characterization of the naloxone cue by investigating if relatively specific antagonists for the mu (naltrexone: $0.10-0.56 \mathrm{mg} / \mathrm{kg}$ ), delta (naltrindole: 1-18 $\mathrm{mg} / \mathrm{kg}$ ), and kappa (MR2266: 1.8$10 \mathrm{mg} / \mathrm{kg}$ ) opioid receptor subtypes will substitute for naloxone in animals trained to discriminate naloxone from its vehicle. The temporal nature of the naloxone cue was examined by varying pretreatment time points $(15,30,45,60 \mathrm{~min})$. Finally, various doses of naltrexone methobromide $(1-18 \mathrm{mg} / \mathrm{kg}$ ) were assessed to determine peripheral mediation of the cue.
\end{abstract}

This work was funded by a grant from the Mellon Foundation to Anthony L. Riley and by the intramural research programs of the National Institute on Drug Abuse and the National Institute on Alcohol Abuse and Alcoholism.

C. M. Davis $(\bowtie) \cdot$ F. Cañadas $\cdot$ A. L. Riley

Psychopharmacology Laboratory, Department of Psychology, American University,

4400 Massachusetts Ave. NW,

Washington, DC 20016, USA

e-mail: cd2994a@american.edu

G. W. Stevenson

University of New England,

Biddeford, ME 04005, USA

T. Ullrich • K. C. Rice

Drug Design and Synthesis Section, Chemical Biology Research Branch,

National Institute on Drug Abuse and National Institute on Alcohol Abuse and Alcoholism,

Rockville, MD 20852, USA
Materials and methods Female Long-Evans rats $(N=30)$ received an injection of naloxone $(1 \mathrm{mg} / \mathrm{kg}$; i.p. $) 15 \mathrm{~min}$ prior to a pairing of saccharin (20-min access) and the emetic $\mathrm{LiCl}(1.8 \mathrm{mEq}$; i.p.; $n=16$, group $\mathrm{NL})$ or vehicle $(n=14$, group $\mathrm{NW})$; on other days, they were injected with saline prior to saccharin alone. Substitution tests with compounds with various receptor affinities and selective CNS and PNS actions were then assessed.

Results Only naloxone and naltrexone produced dosedependent decreases in saccharin consumption. Naloxone administered at 15 and 30 min before saccharin produced decreases in consumption similar to that displayed on training days. Naltrexone methobromide substituted only at the highest dose tested $(18 \mathrm{mg} / \mathrm{kg})$.

Conclusions Naloxone's stimulus effects appear to be mediated centrally via activity at the mu opioid receptor.

Keywords Naloxone $\cdot$ CTA · Drug discrimination .

Opiate-naïve · Rat · Naltrexone · Naltrindole · MR2266 ·

Naltrexone methobromide

Investigating the discriminative stimulus properties of the opioid antagonist naloxone has proven difficult. Morphinenaïve animals find naloxone virtually indiscriminable from saline, and when naloxone does serve as a discriminative cue, high doses and extensive training are needed (Carter and Leander 1982; Lal et al. 1978; Overton and Batta 1979; Weissman 1978). For example, Carter and Leander (1982) demonstrated that pigeons required a lengthy training period (79 sessions, on average) to discriminate a high $(30 \mathrm{mg} / \mathrm{kg}$ ) dose of naloxone from saline. It was hypothesized that failure to obtain this discrimination at lower doses stemmed from the inability of this antagonist to affect operant behavior at low doses, even though low doses of 
naloxone will successfully antagonize opioid agonistinduced behaviors (Bechara et al. 1987; Chen and Pan 2006; Grabus et al. 1999; Negus 2006; White et al. 2005) and will affect other behaviors thought to be mediated by endogenous opioid activity (Levine et al. 2003; Kirkham and Cooper 1988; Michaels and Holtzman 2007; Mucha and Herz 1985; Mucha et al. 1985; Parker and Rennie 1992; Skoubis et al. 2001).

Interestingly, Kautz et al. (1989) reported that opiate-naïve rats readily acquired the discrimination of a low $1 \mathrm{mg} / \mathrm{kg}$ dose of naloxone from saline when trained within the conditioned taste aversion (CTA) baseline of drug discrimination learning (see Mastropaolo et al. 1989; for a review, see Riley 1997). In this baseline, animals were given naloxone prior to a pairing of saccharin with $\mathrm{LiCl}$. On other days, they are given saline (e.g., the naloxone vehicle) prior to saccharin alone. Under these conditions, animals rapidly came to avoid consumption of saccharin when it was preceded by the injection of naloxone and to consume the same saccharin solution when it was preceded by the naloxone vehicle. Control subjects receiving the same naloxone injections, but not receiving the saccharin-LiCl pairings, consumed saccharin following injection of both naloxone and its vehicle. Following acquisition of discriminative control with naloxone, subjects displayed dosedependent generalization to naloxone. Moreover, tests with varying doses of naltrexone produced naloxone-appropriate responding, suggesting that naloxone's discriminative stimulus effects were mediated at the mu opioid receptor. Smurthwaite et al. (1992) further investigated naloxone's $(1 \mathrm{mg} / \mathrm{kg})$ discriminative effects in this design with other opioid antagonists, including naltrexone, diprenorphine, and nalorphine, all with some degree of affinity for the mu opioid receptor, and reported full or partial substitution for the naloxone cue. Both of these studies demonstrated the sensitivity of the CTA baseline of drug discrimination and suggested that naloxone's discriminative stimulus effects are mediated via the mu opioid receptor.

It should be noted, however, that naloxone is considered a general opioid antagonist with affinity for all three $(\mathrm{mu}>$ kappa > delta) opiate receptor subtypes (Leslie 1987) and studies fully characterizing naloxone's discriminative stimulus effects relative to the other opiate receptor subtypes are lacking. It is possible that activity at the delta and/or the kappa receptor subtype mediates some component of naloxone's discriminative effects. In this context, it is interesting to note that naloxone not only antagonizes the discriminative effects of mu receptor agonists such as morphine, fentanyl, and buprenorphine (Colpaert and Janssen 1984; Shannon et al. 1984; Stevenson et al. 1991) but also blocks the discriminative effects of spiradoline, a kappa receptor agonist (Holtzman and Steinfels 1994). Thus, given its binding affinity to all receptor subtypes of the opiate receptor, in the absence of assessing generalization to compounds acting at sites other than mu, it is difficult to conclude the nature of naloxone's discriminative effects.

Accordingly, the present study attempted to further characterize the naloxone cue by investigating the relative contribution of each opioid receptor subtype using the subtype-specific antagonists, naltrexone, naltrindole, and MR2266 in producing naloxone's stimulus effects in female Long-Evans rats. Female rats were employed here to allow comparisons between the present work and earlier studies assessing naloxone discriminative control that also used females (see Kautz et al. 1989; Smurthwaite et al. 1992). Specifically, in the present study, rats were trained to discriminate $1 \mathrm{mg} / \mathrm{kg}$ naloxone from vehicle using the CTA baseline of drug discrimination learning. Once criterion for the discrimination was achieved, various doses of naloxone, naltrexone, naltrindole, and MR2266 were administered to assess the ability of these compounds to generalize to the naloxone cue. Moreover, a time-course analysis was performed by varying the pretreatment time of the training dose to determine the temporal component of naloxone's stimulus effects. In addition to differential receptor activity possibly mediating naloxone's effects, opioid receptors residing in the central or peripheral nervous systems could alone, or in combination, produce naloxone's stimulus effects. In relation to this idea, many behavioral effects of opioid peptides, as well as naloxone, are mediated in the central nervous system. Quaternary derivatives (compounds unable to cross the blood-brain barrier) of these peptides used to examine opioid activity often fail to affect behavior or block opioid-induced effects (Bechara et al. 1987; Brown and Holtzman 1981; Koob et al. 1994; Locke and Holtzman 1985; for a review, see Brown and Goldberg 1985). To test if the discriminative effects of naloxone are mediated via central opioid receptors, animals trained to discriminate naloxone from its vehicle were administered naltrexone methobromide (a quaternary compound with limited ability to access the CNS) in subsequent generalization tests.

\section{Materials and method}

Subjects and apparatus

A total of 30 experimentally naïve, Long-Evans female rats approximately 200-290 g at the beginning of the experiment served as subjects. They were housed in individual wiremesh cages and maintained on a 12:12 L/D cycle and at an ambient temperature of $23^{\circ} \mathrm{C}$ for the duration of the experiment. Rat chow (Prolab Rat, Mouse, Hamster 3000) was available ad libitum. All procedures were in compliance with US National Institutes of Health and National Research 
Council guidelines $(1996,2003)$ and approved by the Animal Care and Use Committee at American University.

\section{Drugs}

Naloxone hydrochloride (generously supplied by DuPont Pharmaceuticals), naltrexone hydrochloride, naltrindole, MR2266, and naltrexone methobromide (generously supplied by the National Institute on Drug Abuse and the National Institute of Diabetes and Digestive and Kidney Diseases) were dissolved in distilled water and injected intraperitoneally (i.p.). The compounds were prepared at the following concentrations: naloxone $(1 \mathrm{mg} / \mathrm{ml})$, naltrexone $(1 \mathrm{mg} / \mathrm{ml})$, naltrindole $(2 \mathrm{mg} / \mathrm{ml})$, MR2266 $(1 \mathrm{mg} / \mathrm{ml})$, and naltrexone methobromide $(1 \mathrm{mg} / \mathrm{ml})$. Lithium chloride (Sigma Pharmaceuticals) was prepared as a $6.4 \mathrm{mg} / \mathrm{ml}$ solution in distilled water. Sodium saccharin (Sigma Pharmaceuticals) was prepared as a $1 \mathrm{~g} / \mathrm{l}$ solution in standard tap water.

Procedure

Phase I: Acquisition At the outset of training, 23.5-h waterdeprived subjects were given 20-min access to water once a day until consumption stabilized (days 1-14). On days 1517 (Saccharin Habituation), a novel saccharin solution replaced water during the daily 20 -min fluid-access period and was preceded on the last day of Saccharin Habituation by an i.p. injection of distilled water $(1 \mathrm{ml} / \mathrm{kg})$. On day 18 , conditioning began. On this day, all subjects were injected with $1 \mathrm{mg} / \mathrm{kg}$ of naloxone $15 \mathrm{~min}$ prior to 20 -min access to saccharin. Immediately following saccharin access, subjects were ranked according to saccharin consumption and assigned to one of two groups such that consumption was comparable between groups. Specifically, subjects in group $\mathrm{NL}$ (naloxone $/ \mathrm{LiCl}, n=16$ ) were injected with $1.8 \mathrm{mEq}$, $0.15 \mathrm{M} \mathrm{LiCl}(76.8 \mathrm{mg} / \mathrm{kg})$, while subjects in group NW (naloxone/water, $n=14$ ) were given an equivolume injection of distilled water (i.e., the $\mathrm{LiCl}$ vehicle) immediately following saccharin access. On the following three recovery days, subjects in both groups were injected with distilled water $15 \mathrm{~min}$ prior to 20 -min access to the same saccharin solution. No injections followed saccharin on these recovery days. This alternating procedure of conditioning and recovery was repeated until discriminative control had been established for all experimental subjects (i.e., each subject in group NL had consumed at least $50 \%$ less than the mean of group NW on two consecutive conditioning trials).

Phase II: Generalization The procedure during this phase was identical to that of phase I with the following exception. On the second day following conditioning (the second recovery day within phase I, but a probe day in this phase), subjects were administered one of a range of doses of naloxone $(0.1-1 \mathrm{mg} / \mathrm{kg})$, naltrexone $(0.1-0.56 \mathrm{mg} / \mathrm{kg})$, naltrindole $(1-18 \mathrm{mg} / \mathrm{kg})$, MR2266 $(1.8-10 \mathrm{mg} / \mathrm{kg})$, and naltrexone methobromide $(1-18 \mathrm{mg} / \mathrm{kg}) 15 \mathrm{~min}$ prior to saccharin access. No injections followed saccharin access on these probe days.

Phase III: Naloxone time course The procedure during this phase was identical to phase II with the following exception. On the second day following conditioning (the second recovery day within phase I, but a probe day in this phase), subjects were administered the training dose of naloxone $(1 \mathrm{mg} / \mathrm{kg}) 15,30,45$, and $60 \mathrm{~min}$ prior to 20-min saccharin access. No injections followed saccharin on these days.

Data analysis

All consumption data for groups NL and NW were analyzed separately by drug or time course using twofactor (Group $\times$ Trial or Group $\times$ Dose) ANOVAs, with the repeated factor being Trial or Dose. Tukey-corrected post hocs or paired samples and independent-samples $t$ tests were used to examine specific within- and between-subject differences.

\section{Results}

Naloxone characterization

Acquisition of naloxone discrimination The two-factor ANOVA revealed significant effects of Group $[F(1,29)=$ 86.581, $p<0.05]$ and Trial $[F(9,261)=17.042, p<0.05]$ and a significant Group $\times$ Trial interaction $[F(9,261)=6.342, p<$ 0.05]. No differences were found in the amount of saccharin consumed on the first conditioning day between groups NL and NW. However, on the second conditioning day, group NL consumed significantly less saccharin than group NW. This difference in consumption continued throughout acquisition. On the eighth conditioning trial, group NL consumed, on average, $50 \%$ less than group NW (4.6 and $9.9 \mathrm{ml}$, respectively), meeting the criterion of acquisition of the discrimination (see Fig. 1, panel a). At this time, generalization and time-course tests began. Consumption on the Recovery Days during acquisition did not differ between groups NL and NW (data not shown).

Naloxone dose substitution The $2 \times 7$ repeated-measures ANOVA revealed a significant effect of Group $[F(1,9)=$ 20.572, $p<0.05]$ and Dose $[F(6,54)=10.855, p<0.05]$ and a significant Group $\times$ Dose interaction $[F(6,54)=6.119, p<$ 0.05]. On the Conditioning Day, group NL drank significantly less saccharin than group NW $[t(10)=10.393, p<$ 
Fig. 1 Naloxone characterization. a Mean saccharin consumption on Conditioning Days for group NL (closed circles) and group NW (open circled). ${ }^{*}$ denote significant between-groups difference. $\dagger$ denotes first conditioning day when group NL met criterion of a $50 \%$ decrease in saccharin consumption relative to group NW. b Mean saccharin consumption for groups NL and NW receiving varying doses of naloxone during dose-substitution tests. $R$ Recovery Day average consumption, $C$ Conditioning Day average consumption. $*$ denotes group NL's Conditioning Day consumption significantly less than group NW's Conditioning Day consumption. ** denotes significant decrease in group NL's consumption compared to group NW at the same dose. \# denotes significantly more saccharin consumed compared to group NL's Conditioning Day consumption. $\dagger$ denotes significantly less saccharin consumed than group NL's Conditioning Day consumption. + denotes significant decrease from group NL's Recovery Day consumption. ${ }^{\wedge}$ denotes a significant decrease in group NW's Conditioning Day consumption relative to its Recovery Day consumption. c Mean saccharin consumption for groups NL and NW receiving naloxone at different pretreatment time points. See b for definition of symbols

0.05; denoted by *; see Fig. 1, panel b] and drank significantly less than its consumption on the Recovery Day $[t(6)=13.984, p<0.05$, denoted by +$]$, showing that group NL was discriminating the naloxone cue from saline. Animals in groups NL and NW drank equivalent amounts of saccharin on the Recovery Day. This discrimination was maintained throughout all testing (significant differences are noted on individual figures for each test; see below). Group NW's consumption on the Conditioning Day was similar to its consumption on the Recovery Day $(p>0.05)$. At the two lowest doses of naloxone $(0.10$ and $0.18 \mathrm{mg} / \mathrm{kg})$, group NL's consumption never differed from that of group NW's. However, at the remaining three doses $(0.32,0.56$, and $1.0 \mathrm{mg} / \mathrm{kg}$ ), group NL's consumption was significantly less than that of group NW's $[t(10)=2.841, p<0.05 ; t(10)=$ 4.383, $p<0.05 ; t(9)=4.453, p<0.05$, respectively; denoted by $* *$. At no point during dose-substitution tests did group NW's consumption differ from its Conditioning Day consumption. Group NL's consumption at $0.32 \mathrm{mg} / \mathrm{kg}$ was significantly less than its own consumption on the Recovery Day $[t(6)=3.606, p<0.05$; denoted by +$]$ but significantly more than its consumption on the Conditioning Day $[t(6)=3.694, p<0.05$; denoted by \#], suggesting that this dose was partially substituting for the $1.0 \mathrm{mg} / \mathrm{kg}$ training dose of naloxone. At the 0.56 and $1.0 \mathrm{mg} / \mathrm{kg}$ doses of naloxone, group NL's consumption did not differ from its Conditioning Day \{but was significantly lower than Recovery Day consumption $[t(6)=7.199, p<0.05 ; t(5)=$ $8.453, p<0.05$; respectively; denoted by +$]\}$, suggesting that these two doses were substituting for the training dose of naloxone $(1 \mathrm{mg} / \mathrm{kg})$. These differential patterns of consumption for groups NL and NW are illustrated in Fig. 1, panel b.

Naloxone time course A $2 \times 6$ repeated-measures ANOVA revealed a significant effect of Group $[F(1,15)=32.329, p<$ a

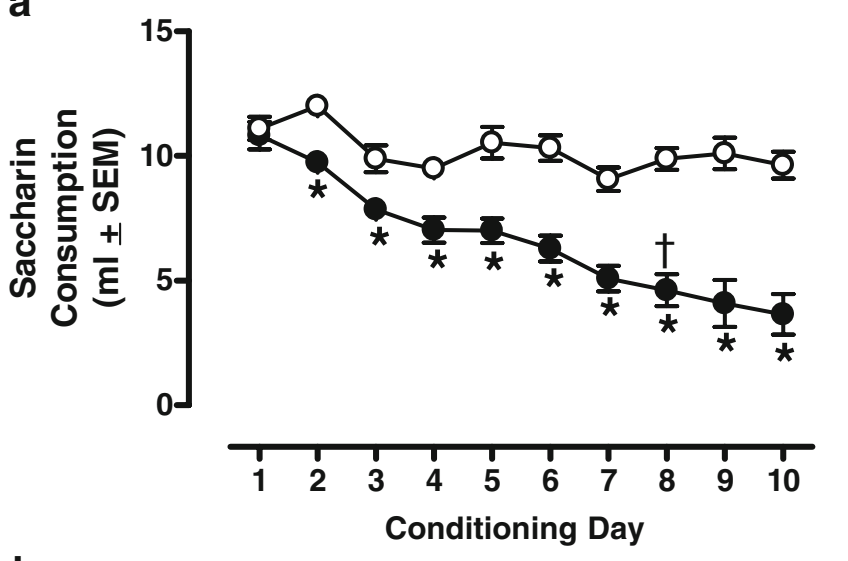

b
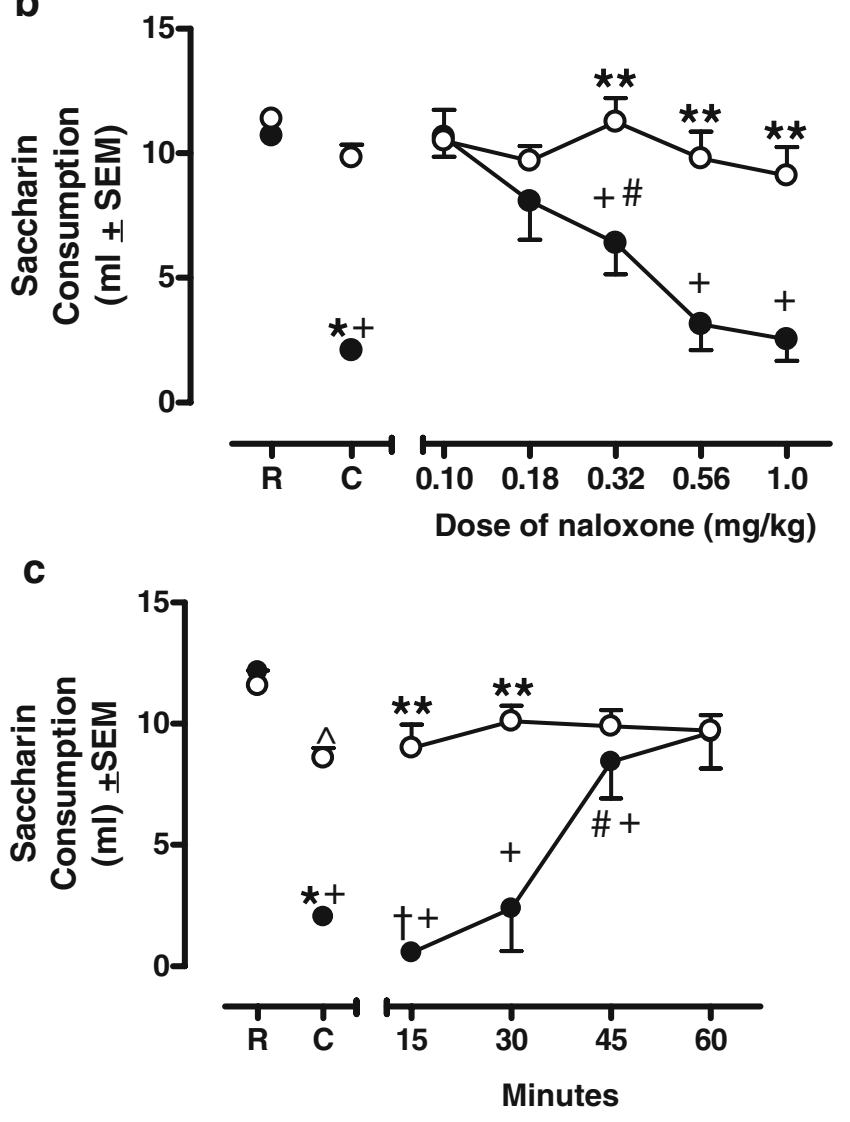

$0.05]$ and Dose $[F(5,75)=22.389, p<0.05]$ as well as a significant Group $\times$ Dose interaction $[F(5,75)=11.696, p<$ 0.05]. Saccharin consumption between these groups differed depending on the pretreatment time of naloxone administration. Group NL drank significantly less saccharin at the 15 and $30 \mathrm{~min}$ pretreatment times compared to group $\mathrm{NW}[t(15)=7.941, p<0.05 ; t(15)=4.357, p<0.05$, respectively; denoted by $* *]$. There were no differences between these groups at 45 and $60 \mathrm{~min}$. Consumption at the $15-\mathrm{min}$ time point for group NL was significantly less than this group's consumption on the Conditioning Day $[t(7)=4.934$, $p<0.05$, denoted by \#] and on the Recovery Day $[t(7)=$ 
26.896, $p<0.05$; denoted by + ]. Naloxone administered 30 min before saccharin access produced consumption similar to its consumption on the Conditioning Day but significantly lower than its consumption on the Recovery Day $[t(7)=4.762, p<0.05$, denoted by +$]$. At the 45 -min pretreatment time, group NL's saccharin consumption was significantly more than its Conditioning Day consumption $[t(7)=4.376, p<0.05$; denoted by \# $]$ but significantly less than its Recovery Day consumption $[t(7)=2.573, p<0.05$, denoted by + ]. Group NL's consumption at the 60-min pretreatment time was significantly greater than consumption on the Conditioning Day $[t(7)=5.612, p<05]$ but was not different from that on the Recovery Day. Group NW's consumption at the 60 -min pretreatment time was similar to its Conditioning Day consumption but significantly less than its Recovery Day consumption $[t(8)=5.121, p<0.05]$. These differential patterns of consumption for groups NL and NW are illustrated in Fig. 1, panel c.

$\mathrm{Mu}$ receptor assessment

Naltrexone generalization A $2 \times 6$ repeated-measures ANOVA revealed significant effects of Group $[F(1,7)=$ $16.230, p<0.05]$ and Dose $[F(5,35)=14.993, p<0.05]$ as well as a significant Group $\times$ Dose interaction $[F(5,35)=$ 5.804, $p<0.05]$. Differences between the groups emerged during the generalization tests with varying doses of naltrexone (see Fig. 2, panel a). Group NL drank significantly less saccharin than group $\mathrm{NW}$ at 0.32 and $0.56 \mathrm{mg} / \mathrm{kg}$ naltrexone $[t(9)=2.944, p<0.05 ; t(10)=3.745$, $p<0.05$; respectively; denoted by $* *]$. Group NL's consumption after $0.18 \mathrm{mg} / \mathrm{kg}$ naltrexone relative to group NW's consumption at this dose approached significance $(p=0.052)$. Consumption by group NL after $0.18,0.32$, and $0.56 \mathrm{mg} / \mathrm{kg}$ naltrexone did not differ from its consumption on the Conditioning Day but was significantly less than that on the Recovery Day (all $p$ 's $<0.05$; denoted by + ), suggesting that all three of these doses generalized to the training drug. Group NW's consumption at each dose of naltrexone was similar to its consumption on the Conditioning Day, showing no overall impairment on consumption (relative to the Conditioning Day only).

Naltrexone methobromide generalization A $2 \times 5$ repeatedmeasures ANOVA revealed a significant effect of Group $[F$ $(1,13)=19.657, p<0.05]$ and Dose $[F(4,13)=65.964, p<$ $05]$ as well as a significant Group $\times$ Dose interaction $[F(4$, $13)=20.460, p<0.05]$. Saccharin consumption did not differ between groups NL and NW when it was preceded by 1 or $10 \mathrm{mg} / \mathrm{kg}$ naltrexone methobromide (all $p$ 's $\geq 0.130$ ). Interestingly, the highest dose of naltrexone methobromide used, $18 \mathrm{mg} / \mathrm{kg}$, produced a significant decrease in saccharin consumption in group NL relative to group NW $[t(15)=$
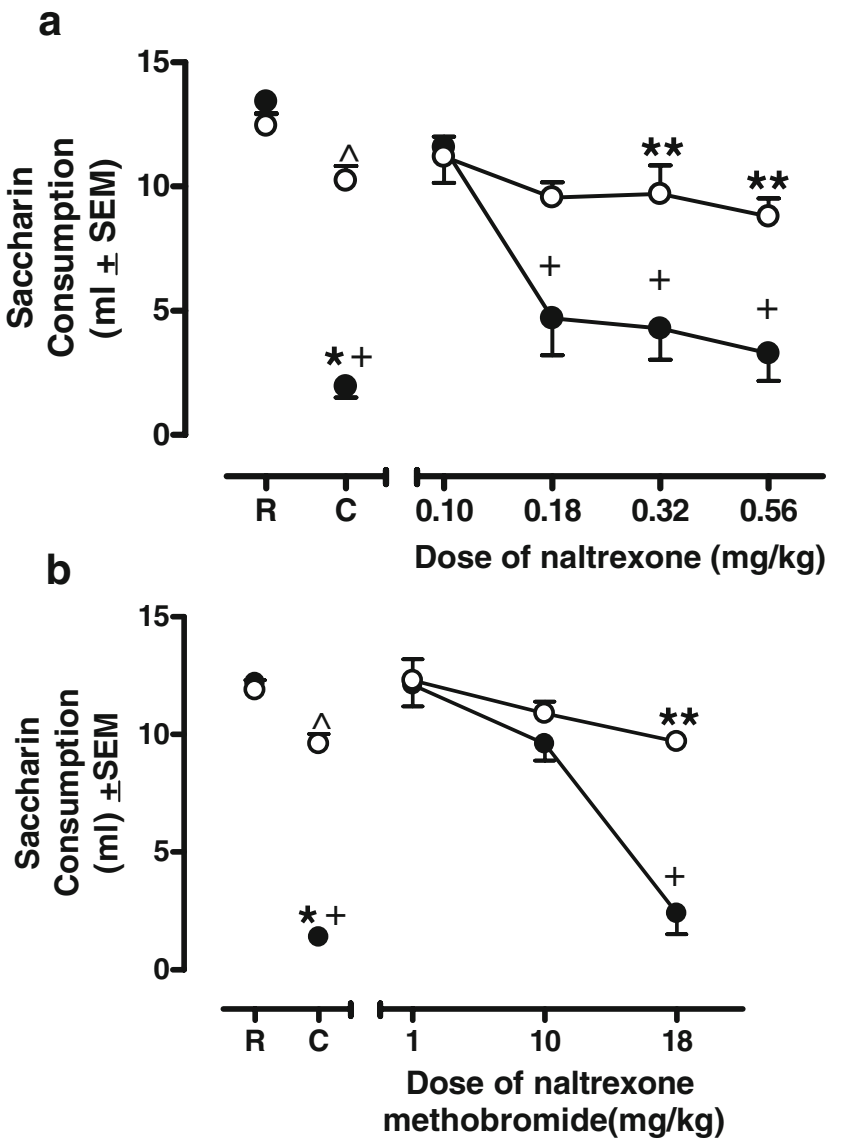

Fig. $2 \mathrm{Mu}$ receptor assessment. a Mean saccharin consumption for groups NL and NW receiving varying doses of naltrexone. b Mean saccharin consumption for groups NL and NW receiving varying doses of naltrexone methobromide. See Fig. 1b for definition of symbols

7.502, $p<0.05$, denoted by $\left.{ }^{* *}\right]$. Moreover, consumption following the $18 \mathrm{mg} / \mathrm{kg}$ dose of naltrexone methobromide in group NL was similar to that on Conditioning Day but lower than that on the Recovery Day $[t(6)=12.949, p<$ 0.05 , denoted by +$]$, suggesting that the highest dose of naltrexone methobromide generalized to the naloxone cue. Also, at the high dose, group NW's consumption was significantly less than its Recovery Day consumption $[t(8)=$ $2.672, p<0.05]$ but significantly more than its Conditioning Day consumption $[t(8)=3.805, p<0.05]$. These differential patterns of consumption for groups NL and NW are illustrated in Fig. 2, panel b.

Delta and kappa receptor assessment

Naltrindole generalization A $2 \times 7$ repeated-measures ANOVA revealed a significant effect of Group $[F(1,9)=$ $7.281, p<0.05]$ and Dose $[F(6,54)=43.681, p<0.05]$ as well as a significant Group $\times$ Dose interaction $[F(6,54)=$ $11.710, p<0.05]$. At the varying doses of naltrindole, only 
the $5.6 \mathrm{mg} / \mathrm{kg}$ dose produced a significant decrease in group NL's consumption relative to group NW's consumption $[t(10)=2.893, p<0.05$; denoted by $* *]$. However, consumption by group NL at this dose did not differ from its own Recovery Day consumption and was significantly greater than its consumption on the Conditioning Day $(p<0.05$; denoted by \#), suggesting that animals in group $\mathrm{NL}$ were not generalizing the $5.6 \mathrm{mg} / \mathrm{kg}$ dose of naltrindole to the training dose of naloxone. At the $18 \mathrm{mg} / \mathrm{kg}$ dose of naltrindole, both groups NL and group NW decreased consumption relative to the amount consumed on Recovery Day (all $p$ 's $<0.05$ ), suggesting that naltrindole produced an unconditioned suppression of consumption (see Fig. 3, panel a).

MR2266 generalization A $2 \times 6$ repeated-measures ANOVA revealed a significant effect of Dose $[F(5,65)=45.460, p<$ $0.05]$ and a significant Group $\times$ Dose interaction $[F(5,65)=$ $18.397, p<0.05]$. No other differences emerged in saccharin consumption between groups NL and NW, suggesting that MR2266 in the dose range used did not generalize to the

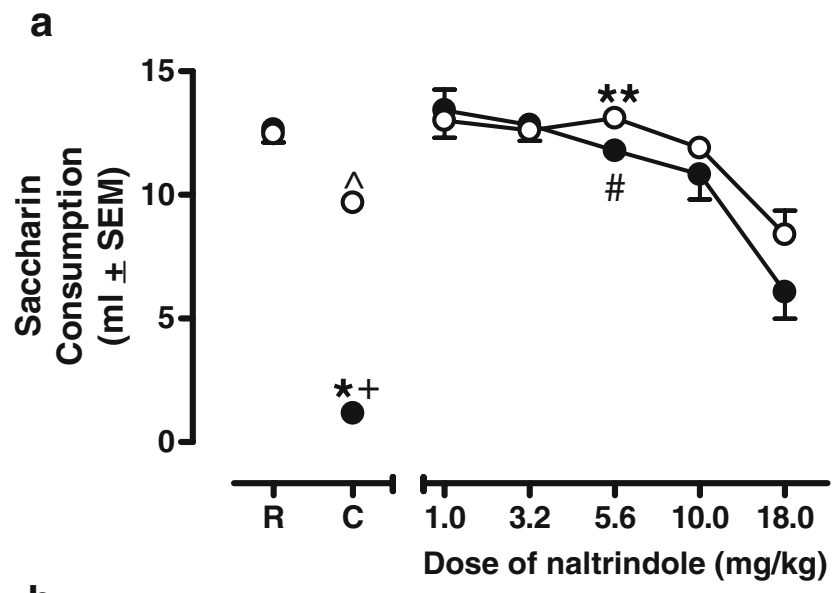

b

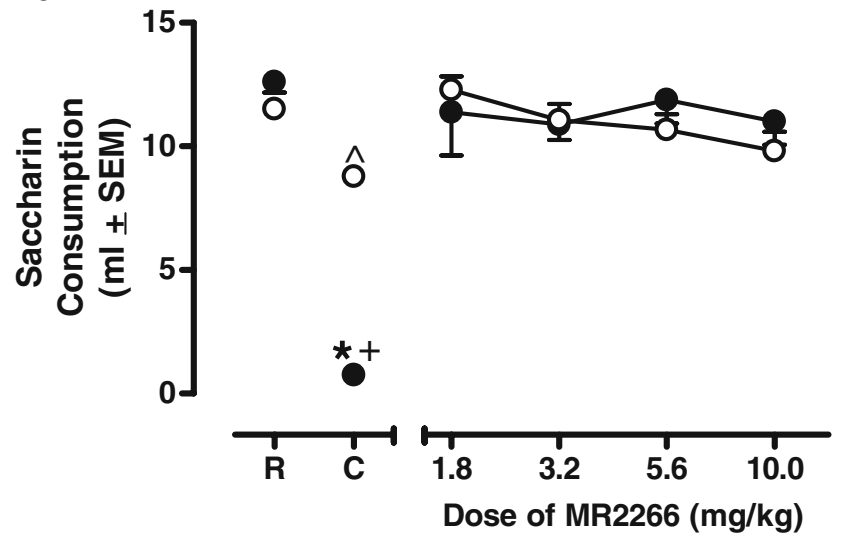

Fig. 3 Kappa and delta receptor assessment. a Mean saccharin consumption by groups NL and NW after varying doses of naltrindole. b Mean saccharin consumption for groups NL and NW after varying doses of MR2266. See Fig. 1b for definition of symbols training dose of naloxone and had no overall impairments on saccharin consumption (see Fig. 3, panel b).

\section{Discussion}

The present study demonstrated that naloxone can serve as a discriminative stimulus in the CTA baseline of drug discrimination learning and that the stimulus effects of naloxone are mediated via mu opioid receptors located within the central nervous system. As described, animals quickly acquired the naloxone discrimination, consuming $50 \%$ or less saccharin relative to control animals within eight conditioning trials. During dose-substitution tests with naloxone, subjects discriminating naloxone from saline displayed dose-dependent decreases in saccharin consumption as the dose of naloxone increased, suggesting naloxoneappropriate responding. Partial generalization to the naloxone stimulus occurred at a dose of $0.32 \mathrm{mg} / \mathrm{kg}$, with full generalization to the training dose occurring at both 0.56 and $1.0 \mathrm{mg} / \mathrm{kg}$ naloxone. These results are consistent with those of Kautz et al. (1989) who demonstrated that these three doses of naloxone generalize to the $1 \mathrm{mg} / \mathrm{kg}$ naloxone cue in the CTA baseline of DDL. Naloxone administration at 15 and $30 \mathrm{~min}$ prior to saccharin occasioned drug-appropriate responding. Consumption at both of these time points (15 and $30 \mathrm{~min}$ ) was significantly less than that of group NW, indicating that the suppression of consumption was not due to an unconditioned effect of naloxone but instead was a function of naloxone's stimulus control. This control was no longer evident at the 45- and 60-min periods. These results parallel those of Carter and Leander (1982) who reported that the stimulus effects of naloxone $(30 \mathrm{mg} / \mathrm{kg}$ given with a 15 -min pretreatment time) had a rapid onset (within $5 \mathrm{~min}$ ) and were of short duration, occasioning $75 \%$ naloxoneappropriate responding at $30 \mathrm{~min}$ but only $50 \%$ naloxoneappropriate responding at $60 \mathrm{~min}$ (the 45 -min time point was not tested). Naloxone can clearly serve as a discriminative stimulus in opioid-naïve animals in the CTA baseline of drug discrimination learning, and its stimulus effects are dose dependent and of relatively short duration (Kautz et al. 1989; Smurthwaite et al. 1992).

Consistent with prior work assessing the generalization of compounds with relative selectivity at the mu receptor (see Smurthwaite et al. 1992), naltrexone occasioned naloxone-appropriate responding. This generalization was evident at 0.32 and $0.56 \mathrm{mg} / \mathrm{kg}(0.18 \mathrm{mg} / \mathrm{kg}$ partially generalized). Interestingly, naltrexone methobromide, a peripherally acting antagonist, only generalized to the naloxone cue at a dose $(18 \mathrm{mg} / \mathrm{kg})$ roughly 50 times greater than that required for generalization by naltrexone. The fact that doses of naltrexone methobromide comparable 
to those of naltrexone failed to generalize to naloxone suggests that the naloxone cue is centrally mediated, especially given that naltrexone methobromide has been shown to be as effective as naloxone and naltrexone in other preparations when administered i.c.v. (Katovich et al. 1986; Locke and Holtzman 1985). That this relatively high dose of $18 \mathrm{mg} / \mathrm{kg}$ naltrexone methobromide engendered naloxone-appropriate responding is consistent with the position that quaternary derivatives might slowly diffuse across the blood-brain barrier, and when given in high doses, this diffusion may be enough to cause central nervous system receptor binding (Brown and Goldberg 1985). For example, a high dose of naloxone methobromide administered systemically is able to lower rectal temperatures (hypothesized to be a centrally mediated thermoregulatory response) but to a lesser degree than systemic naloxone, suggesting that some of this compound might diffuse into the brain (Katovich et al. 1986). Although the mu antagonist naltrexone generalized to naloxone, the delta receptorselective antagonist naltrindole did not. In fact, naltrindole engendered saline-appropriate responding at all doses tested. Only one dose, $5.6 \mathrm{mg} / \mathrm{kg}$, produced a significant decrease in saccharin consumption in group NL relative to group NW; however, consumption at this point was not different from group NL's Recovery Day consumption, suggesting that this difference was not due to any generalization to the naloxone cue. Similarly, the relatively selective kappa antagonist MR2266 failed to generalize to naloxone at any dose tested. These failures to generalize were not a function of the specific doses of naltrindole and MR2286 being behaviorally inactive. As noted, the highest dose of naltrindole suppressed consumption relative to that on recovery days (in both groups $\mathrm{NL}$ and $\mathrm{NW}$ ); there was simply no additional suppression produced by discriminative control of consumption. Further, although MR2266 did not produce significant decreases in consumption in groups NL and NW, these doses have been shown to affect behavior in other preparations (Bechara and van der Kooy 1987; Fanselow et al. 1989; Pournagash and Riley 1993; 1995). These selective generalization patterns indicate that naloxone's stimulus effects are centrally mediated at the mu receptor subtype with minimal (if any) mediation via the delta and kappa receptors.

Although the present study has characterized naloxone's stimulus effects as due to its antagonism of central mu opioid receptors, the basis for its effects remains unknown. One possibility is that naloxone produces its stimulus effects in opiate-naïve animals by an interaction with the endogenous opioid system, specifically by its blocking of endogenous opiate tone. It is instructive in this context to turn to other investigations of naloxone in drug discrimination learning. As noted earlier, although there is little evidence outside the taste aversion baseline of drug discrimination learning that naloxone is an effective cue in opiate-naive animals (see Carter and Leander 1982; Lal et al. 1978; Overton and Batta 1979; Weissman 1978), naloxone, as well as other opiate antagonists, readily serves a discriminative function in opiate-dependent subjects. In these instances, it is likely that naloxone's stimulus effects are a function of precipitated withdrawal (Holtzman 1985; McMahon et al. 2004; Medvedev et al. 1998; Sell et al. 2003; although see Miksic et al. 1981). Although the stimulus effects of naloxone in opiate-naïve and opiatedependent animals stem from its ability to block endogenous and exogenous opioid activity at opioid receptors (Carter and Leander 1982; Holtzman 1985; McMahon et al. 2004), it is not known if the stimulus effects are the same in animals with and without an opiate history (see Valentino et al. 1983). Naloxone-precipitated withdrawal is assumed to be aversive (see McDonald et al. 1997; Parker et al. 2002), an effect thought to mediate its stimulus effects in dependent animals. It is not clear if the stimulus effects in opiate-naïve animals are due to any dysphoria produced by blocking endogenous tone. Interestingly, naloxone can induce conditioned taste and place aversions in opiate-naive subjects, suggesting that it does have aversive effects, even in such rats (Mucha and Herz 1985; Mucha et al. 1985; Mucha and Walker 1987; Parker and Rennie 1992; Stolerman et al. 1978; for a review, see Stolerman and D'Mello 1981). Whether the subjective effects produced by naloxone across these different conditions reflect qualitative differences or variations in affective states as a function of changes in opioid activity has yet to be determined.

Independent of the nature of the naloxone cue, it is clear that its subjective effects can be used to control behavior. Further, the fact that these effects can be reliably demonstrated in the taste aversion baseline of drug discrimination learning allows this subjective effect to be characterized (receptor mediation, temporal duration). Demonstrating the specific nature of this effect may require systematic comparisons of the effects of various manipulations in opiate-naïve and opiate-experienced animals to determine any parallels in changes of these discriminative effects with pharmacological challenges or manipulations known to impact endogenous opiate activity.

\section{References}

Bechara A, van der Kooy D (1987) Kappa receptors mediate the peripheral aversive effects of opiates. Pharmacol Biochem Behav 28:227-233

Bechara A, Zito KA, van der Kooy D (1987) Peripheral receptors mediate the aversive conditioning effects of morphine in the rat. Pharmacol Biochem Behav 28:219-225

Brown DR, Goldberg LI (1985) The use of quaternary antagonists in opiate research. Neuropharmacology 24:181-191 
Brown DR, Holtzman SG (1981) Opiate antagonists: central sites of action in suppressing water intake of the rat. Brain Res 221:432436

Carter RB, Leander JD (1982) Discriminative stimulus properties of naloxone. Psychopharmacology (Berl) 77(4):305-308

Chen SR, Pan HL (2006) Blocking mu opioid receptors in the spinal cord prevents the analgesic action by subsequent systemic opioids. Brain Res 1081(1):119-125

Colpaert FC, Janssen PA (1984) Agonist and antagonist effects of prototype opiate drugs in rats discriminating fentanyl from saline: characteristics of partial generalization. J Pharmacol Exp Ther 230:193-199

Fanselow MS, Calcagnetti DJ, Helmstetter FJ (1989) Modulation of appetitively and aversively motivated behavior by the kappa opioid antagonist MR2266. Behav Neurosci 103:663-672

Grabus SD, Smurthwaite ST, Riley AL (1999) Nalorphine's ability to substitute for morphine in a drug discrimination procedure is a function of training dose. Pharmacol Biochem Behav 63:481-488

Holtzman SG (1985) Discriminative stimulus effects of morphine withdrawal in the dependent rat: suppression by opiate and nonopiate drugs. J Pharmacol Exp Ther 233:80-86

Holtzman SG, Steinfels GF (1994) Antagonism of the discriminative stimulus effects of the kappa-opioid agonist spiradoline. Psychopharmacology (Berl) 116:243-248

Katovich MJ, Simpkins JW, O’Meara J (1986) Effects of opioid antagonists and their quaternary analogs on temperature changes in morphine-dependent rats. Life Sci 39:1845-1854

Kautz MA, Geter B, McBride SA, Mastropaolo JP, Riley AL (1989) Naloxone as a stimulus for drug discrimination learning. Drug Dev Res 16:317-326

Kirkham TC, Cooper SJ (1988) Naloxone attenuation of sham feeding is modified by manipulation of sucrose concentration. Physiol Behav 44:491-494

Koob GF, Pettit HO, Ettenberg A, Bloom FE (1994) Effects of opiate antagonists and their quaternary derivatives on heroin selfadministration in the rat. J Pharmacol Exp Ther 229:481-486

Lal H, Miksic S, McCarten M (1978) A comparison of discriminative stimuli produced by naloxone, cyclazocine and morphine in the rat. In: Colpaert FC, Rosecrans JA (eds) Stimulus properties of drugs: ten years of progress. Elsevier, Amsterdam, pp 177-180

Leslie FM (1987) Methods used for the study of opioid receptors. Pharmacol Rev 39:197-249

Levine AS, Kotz CM, Gosnell BA (2003) Sugars: hedonic aspects, neuroregulation, and energy balance. Am J Clin Nutr 78 (suppl):834S-842S

Locke KW, Holtzman SG (1985) Characterization of the discriminative stimulus effects of centrally administered morphine in the rat. Psychopharmacology (Berl) 87:1-6

Mastropaolo JP, Moskowitz KH, Dacanay RJ, Riley AL (1989) Conditioned taste aversions as a behavioral baseline for a drug discrimination learning: an assessment with phencyclidine. Pharmacol Biochem Behav 32:1-8

McDonald RV, Parker LA, Siegel S (1997) Conditioned sucrose aversions produced by naloxone-precipitated withdrawal from acutely administered morphine. Pharmacol Biochem Behav 58:1003-1008

McMahon LR, Sell SL, France CP (2004) Cocaine and other indirectacting monoamine agonists differentially attenuate a naltrexone discriminative stimulus in morphine-treated rhesus monkeys. J Pharmacol Exp Ther 308:111-119

Medvedev IO, Dravolina OA, Bespalov AY (1998) Effect of $N$ methyl-D-aspartate receptor antagonists on discriminative stimulus effects of naloxone in morphine-dependent rats using the Y-maze drug discrimination paradigm. J Pharmacol Exp Ther 286:1260 1268
Michaels CC, Holtzman SG (2007) Enhanced sensitivity to naltrexone-induced drinking suppression of fluid intake and sucrose consumption in maternally separated rats. Pharmacol Biochem Behav 86:784-796

Miksic S, Sherman G, Lal H (1981) Discriminative response control by naloxone in morphine pretreated rats. Psychopharmacology (Berl) 72:179-184

Mucha R, Herz A (1985) Motivational properties of kappa and mu opioid receptor agonists studied with place and taste preference conditioning. Psychopharmacology (Berl) 86:274-280

Mucha RF, Walker MJ (1987) Aversive property of opioid receptor blockade in drug-naïve mice. Psychopharmacology (Berl) 93:483-488

Mucha RF, Millan MJ, Herz A (1985) Aversive properties of naloxone in non-dependent (naïve) rats may involve blockade of central $\beta$ endorphin. Psychopharmacology (Berl) 86:281-285

National Research Council (1996) Guide for the care and use of laboratory animals. National Academy, Washington DC

National Research Council (2003) Guidelines for the care and use of mammals in neuroscience and behavioral research. National Academy, Washington DC

Negus SS (2006) Choice between heroin and food in nondependent and heroin-dependent rhesus monkeys: effects of naloxone, buprenorphine, and methadone. J Pharmacol Exp Ther 317:711-723

Overton DA, Batta SK (1979) Investigation of narcotics and antitussives using drug discrimination techniques. J Pharmacol Exp Ther 211:401-408

Parker LA, Rennie M (1992) Naltrexone-induced aversions: assessment by place conditioning, taste reactivity, and taste avoidance paradigms. Pharmacol Biochem Behav 41:559-565

Parker LA, Cyr JA, Santi AN, Burton PD (2002) the aversive properties of acute morphine dependence persist $48 \mathrm{~h}$ after a single exposure to morphine: evaluation by taste and place conditioning. Pharmacol Biochem Behav 72:87-92

Pournagash S, Riley AL (1993) Buprenorphine as a stimulus in drug discrimination learning: an assessment of mu and kappa receptor activity. Pharmacol Biochem Behav 46:593-604

Pournagash S, Riley AL (1995) The effects of chronic morphine on the generalization of buprenorphine stimulus control: an assessment of kappa antagonist activity. Pharmacol Biochem Behav 52:779-787

Riley AL (1997) Drug discrimination learning: assessment of opioid receptor pharmacology. In: Bouton ME, Fanselow MS (eds) Learning, motivation, and cognition: the functional behaviorism of Robert C. Bolles. American Psychological Association, Washington, DC, pp 225-254

Sell SL, McMahon LR, France CP (2003) Relative efficacy of buprenorphine, napbuphine and morphine in opioid-treated rhesus monkeys discriminative naltrexone. J Pharmacol Exp Ther 306:1167-1173

Shannon HE, Cone EJ, Gorodetzky CW (1984) Morphine-like discriminative stimulus effects buprenorphine and demethoxybuprenorphine in rats: quantitative antagonism by naloxone. J Pharmacol Exp Ther 229:768-774

Skoubis PD, Matthes HW, Walwyn WM, Kieffer BL, Maidment NT (2001) Naloxone fails to produce conditioned place aversion in $\mathrm{m}$-opioid receptor knock-out mice. Neuroscience 106:757-763

Smurthwaite ST, Kautz MA, Geter B, Riley AL (1992) Naloxone as a stimulus in drug discrimination learning: generalizations to other opiate antagonists. Pharmacol Biochem Behav 41(1):43-47

Stevenson GW, Pournaghash S, Riley AL (1991) Antagonism of drug discrimination learning within the conditioned taste aversion procedure. Pharmacol Biochem Behav 41:245-249

Stolerman IP, D'Mello G (1981) Oral self-administration and the relevance of conditioned taste aversions. In: Thompson T, Dews 
PB, McKim WA (eds) Advances in behavioral pharmacology, vol 3. Academic, New York, pp 169-214

Stolerman IP, Pilcher CW, D'Mello G (1978) Aversive properties of narcotic antagonists in rats. Neuropharmacology 17:427

Valentino RJ, Herling S, Woods JH (1983) Discriminative stimulus effects of naltrexone in narcotic-naïve and morphine-treated pigeons. J Pharmacol Exp Ther 224:307-313
Weissman A (1978) The discriminability of naloxone in rats depends on concomitant morphine treatment. In: Colpaert FC, Rosecrans JA (eds) Stimulus properties of drugs: ten years of progress. Elsevier, Amsterdam, pp 209-214

White DA, Hwang ML, Holtzman SG (2005) Naltrexone-induced conditioned place aversion following a single dose of morphine in the rat. Pharmacol Biochem Behav 81:451-458 